\title{
AC 2010-1647: A CROSS CURRICULAR NUMERICAL AND EXPERIMENTAL STUDY IN HEAT TRANSFER
}

Timothy Doughty, University of Portland

Steven O'Halloran, University of Portland 


\title{
A Cross Curricular Numerical and Experimental Study in Heat Transfer
}

\begin{abstract}
In this study, the integration of numerical and experimental analyses for the heat transfer of a cooling cylinder is revisited. In the spring of their Junior year, students in an introductory heat transfer course are asked to perform a numerical analysis of the cooling phenomenon for the free convection of cooling cylinder. The students study both aluminum and acrylic cylinders, affording students the opportunity to test the validity of the lumped capacitance model for the system. In the fall of their senior year, the same students in a technical elective Systems and Measurement course are asked to design and conduct an experiment to validate their simulation. This includes generating LabVIEW code, setting data acquisition parameters, and determining appropriate post processing for the data. Additionally, students are given a review of their numerical study just prior to their experimental work. Analysis of their performance and an assessment of survey results are used to determine the degree to which the integrated exercise has been appreciated.
\end{abstract}

\section{Introduction}

This paper documents a heat transfer project that incorporates both numerical analysis (finite difference) and experimental testing to teach basic concepts of conduction and convection. In the project, a heated small aluminum cylinder and a small acrylic cylinder are cooled and the temperature of the cylinders through time is calculated (numerical analysis) and measured (experimental testing). This project was done over the span of two undergraduate courses, a required introductory heat transfer lecture course (ME 336 Heat Transfer) and a senior level technical elective on instrumentation (ME 491 Systems and Measurement). The goal of the project is to reinforce concepts of conduction and convection heat transfer through computational methods and experimental testing. The project was separated into two courses for the following reasons. First, in a single course it is often not possible to have enough time to conduct detailed numerical analysis and time intensive experiments, especially for a lecture oriented course. Second, by using two separate courses the students can see the relationship between different engineering courses and strengthen their appreciation of their curriculum. This project has been done by the authors once before ${ }^{1}$ and several improvements were included in this study. In addition to documenting the project, a student survey was given to determine the effectiveness of the project in reinforcing fundamental heat transfer concepts related to convection and conduction.

Computational methods often work very well to solve heat transfer problems and several recent studies have shown this effectiveness ${ }^{2,3,4,5}$. Even though computational methods are valuable, hands-on learning through conducting experiments is also an important teaching tool ${ }^{6}$. Therefore, there is an effort to develop laboratory work that supplements numerical investigations in the field ${ }^{7}$. 
In both the numerical analysis and the experimental testing, students work in groups of two to four students. This was done to promote teamwork and it has also been found that groups close to four in size are preferential from a learning point of view ${ }^{8}$.

This work is an improvement upon previous work by the authors ${ }^{1}$. Several changes were made. First, the timing between the two courses was changed. Previously, the courses were held one year apart in the Spring semester of separate years. It was determined that this delay was undesirable, therefore now the Heat Transfer course is in the Spring semester and the Systems and Measurement course was held in the following Fall semester. The courses were separated by the summer break, but this is an improvement on the previous timing.

Second, simulation of the acrylic cylinder was added to both the numerical analysis and the experimental measurements. This was done to highlight the difference between material properties and the effect on the centerline and surface temperature distribution.

Third, there was a stronger focus on the use of data acquisition through a LabVIEW tutorial that the students participated in during the Systems and Measurement course.

This paper is divided into five sections. Following this introduction, the numerical analysis is given along with the results for that part. Next, the experimental testing is described in detail along with the associated results. After that, the results of a student survey designed to quantify the effectiveness of the two-part project are presented with a discussion of the results. These results are compared to previous results to help determine effectiveness of changes made to the project. Finally, the conclusion is presented.

\section{Theoretical Analysis and Finite Difference Simulation}

A semester project involving writing a finite difference code to determine the temperature (centerline and surface) of a small aluminum cylinder and a small acrylic cylinder was assigned to introductory heat transfer students. The project demonstrates heat transfer concepts of conduction and convection as well as numerical solutions to time-dependant partial differential equations. The geometry of the cylinder is shown in Figure 1. 


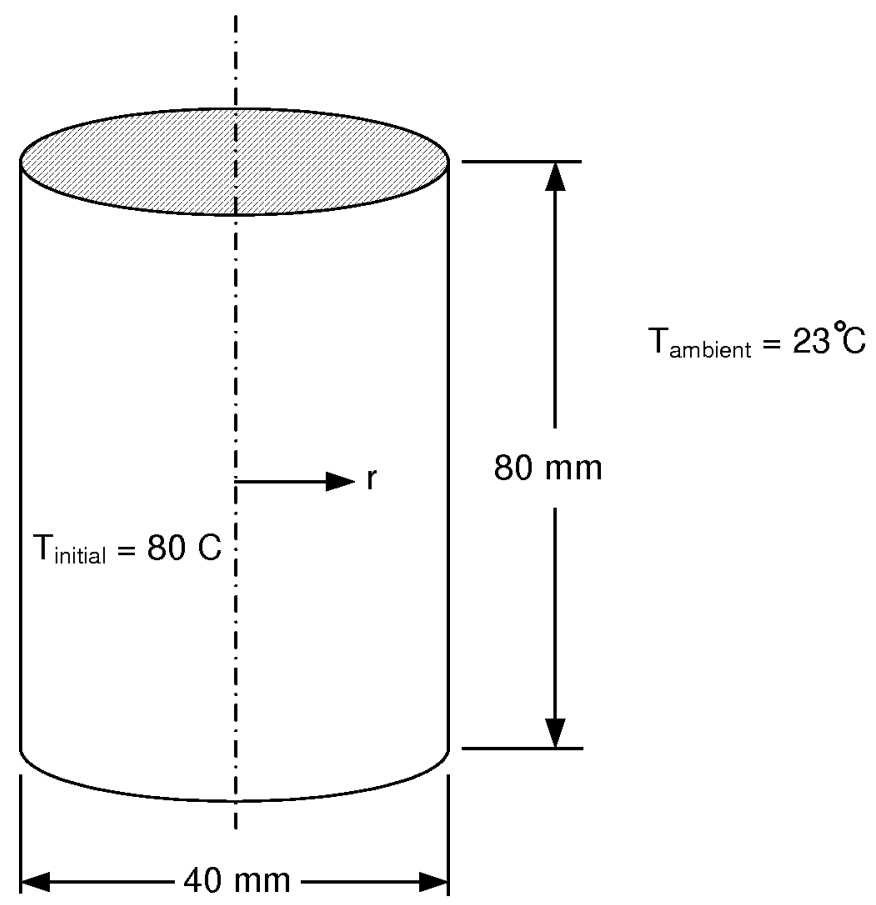

Figure 1: Geometry of cylinder.

The diameter of the cylinder is $40 \mathrm{~mm}$, the height is $80 \mathrm{~mm}$ and the material is T2024-T6 for the aluminum cylinder and Plexiglas for the acrylic cylinder. The initial temperature of both cylinders is $80^{\circ} \mathrm{C}$. The cylinders are assumed to be insulated on the top and bottom, so that heat transfer occurs only through the sides of the cylinder. The cylinders are allowed to cool by free convection to the room which is at a temperature of $23^{\circ} \mathrm{C}$.

Inside of the cylinder, the governing equation for the temperature is given below assuming only radial conduction?.

$$
\rho \mathrm{c}_{\mathrm{p}} \frac{\partial \mathrm{T}}{\partial \mathrm{t}}=\mathrm{k}\left[\frac{1}{\mathrm{r}} \frac{\partial}{\partial \mathrm{r}}\left(\mathrm{r} \frac{\partial \mathrm{T}}{\partial \mathrm{r}}\right)\right]
$$

At the surface of the cylinder, conduction within the cylinder equals convection as given below.

$$
\begin{gathered}
\mathrm{q}_{\text {conduction }}=\mathrm{q}_{\text {convection }} \\
-\left.\mathrm{k} \frac{\partial \mathrm{T}}{\partial \mathrm{t}}\right|_{\mathrm{r}=\mathrm{R}}=-\mathrm{h} \mathbf{C}_{\text {surface }}-\mathrm{T}_{\text {surroundings }}-
\end{gathered}
$$

The temperature distribution in the cylinder is symmetric, therefore at the centerline the following equation can be used:

$$
\left.\frac{\partial \mathrm{T}}{\partial \mathrm{t}}\right|_{\mathrm{r}=0}=0
$$


Equations (1), (2), and (3) are the governing equations for the problem. To solve the set of equations, a finite difference approach is used for the time and spatial derivatives. A first order forward difference is used for time along with second order centered differences for the spatial terms as listed in equations (4), (5), and (6) below ${ }^{10}$.

$$
\begin{gathered}
\frac{\partial \mathrm{T}}{\partial \mathrm{t}}=\frac{1}{\Delta \mathrm{t}} \mathbf{C}^{\mathrm{t}_{\text {new }}-\mathrm{T}^{\mathrm{t}}}- \\
\frac{\partial^{2} \mathrm{~T}}{\partial \mathrm{t}^{2}}=\frac{1}{\Delta \mathrm{r}^{2}} \mathbf{C}_{\mathrm{r}+1}-2 \mathrm{~T}_{\mathrm{r}}+\mathrm{T}_{\mathrm{r}-1}- \\
\frac{\partial \mathrm{T}}{\partial \mathrm{r}}=\frac{1}{2 \Delta \mathrm{r}} \mathbf{C}_{\mathrm{r}+1}-\mathrm{T}_{\mathrm{r}-1}-
\end{gathered}
$$

The subscripts in the equations above represent node numbers for the finite difference solution while superscripts represent the time for each nodal temperature. Also, $\Delta \mathrm{r}$ is the spacing between each radial element and is specified to be $1.0 \mathrm{~mm}$. The time step, $\Delta \mathrm{t}$, is not specified in the problem, but students experiment to determine a good value. To provide numerical stability of the solution a $\Delta \mathrm{t}$ of approximately 0.0002 seconds or less is needed.

The overall results of the project were successful. Each group of students submitted a final report and they also demonstrated their finite difference program to the instructor. Most students utilized MATLAB to create a program to iteratively solve for the temperature distribution. A few students used Microsoft Excel to solve for the temperature distribution. The finite difference equations can be entered into Excel relatively easily. However, the project typically requires over 500,000 time steps, therefore, calculating time can be very lengthy using Excel. Recent improvement in Excel have made it a more viable option though. An earlier version (Excel 2003 and older) had a limitation of approximately 65,000 rows per worksheet, making calculations very difficult for a larger number of time steps. The most recent version (Excel 2007) now allows for over 1,000,000 rows per worksheet.

The students were not given the heat transfer coefficient (h) for the problem, but they were able to use their program along with a set of experimental data provided to estimate the heat transfer coefficient. A trial and error approach was used. Modeling the system as free convection with air, students were able to predict the heat transfer coefficient will likely be in the range of 2-25 $\mathrm{W} / \mathrm{m}^{2} \mathrm{~K}$. The students found the convection coefficient to be approximately $13 \mathrm{~W} / \mathrm{m}^{2} \mathrm{~K}$. The same heat transfer coefficient was used for the aluminum cylinder cooling and acrylic cylinder cooling.

Representative final results for the project are shown in Figure 2 (aluminum cylinder) and Figure 3 (acrylic cylinder). The calculated centerline and surface temperature are plotted as a function of time along with the experimental data. It can be seen that the centerline and surface temperature of the aluminum cylinder are almost identical. The students were asked to comment on this observation. Due to the high thermal conductivity of the aluminum and the dimensions and heat transfer coefficient involved, there is a very small temperature gradient inside of the 
cylinder. This can be predicted ahead of time by calculating the Biot number ( $\mathrm{Bi}$ ) of the cylinder.

$$
\mathrm{Bi}=\frac{\mathrm{h} \cdot\left(\frac{\mathrm{R}}{2}\right)}{\mathrm{k}}
$$

Where, Bi: Biot number

$\mathrm{h}$ : heat transfer coefficient $\left(13 \mathrm{~W} / \mathrm{m}^{2} \mathrm{~K}\right)$

$\mathrm{r}$ : radius of cylinder $(0.02 \mathrm{~m})$

$\mathrm{k}$ : thermal conductivity of cylinder $(177 \mathrm{~W} / \mathrm{m} \cdot \mathrm{K}$ for aluminum and $0.19 \mathrm{~W} / \mathrm{m} \cdot \mathrm{K}$ for acrylic cylinder)

This results in $\mathrm{Bi}=0.00073$ for the aluminum cylinder and $\mathrm{Bi}=0.68$ for the acrylic cylinder. Since $\mathrm{Bi}_{\text {aluminum }}<0.1$, the centerline and surface temperature will be approximately the same for the aluminum cylinder whereas since $\mathrm{Bi}_{\mathrm{acrylic}}>0.1$, the centerline and surface temperature will be noticeably different for the acrylic cylinder. This can be seen in Figure 2 and Figure 3.

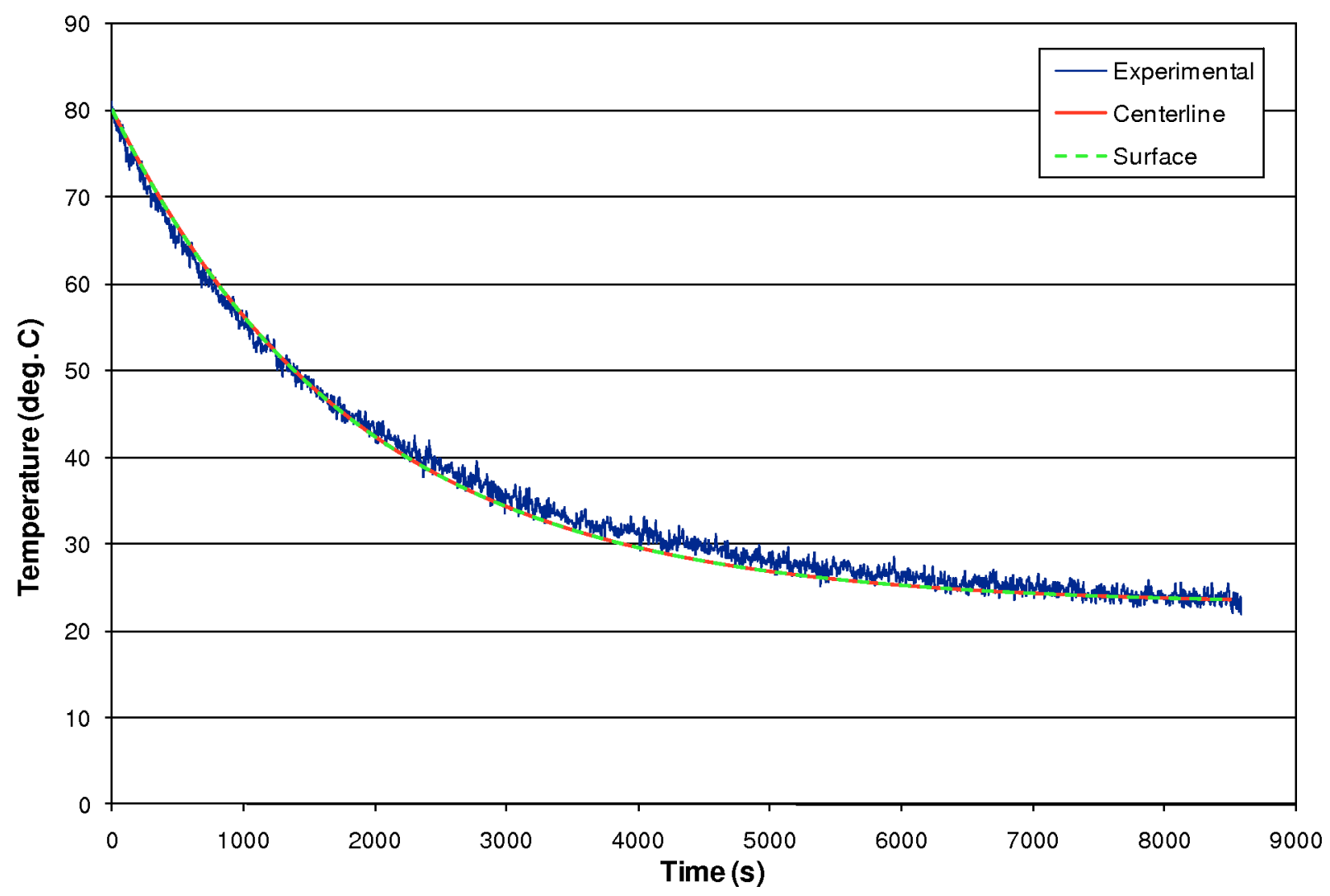

Figure 2: Temperature distribution of aluminum cylinder with time. 


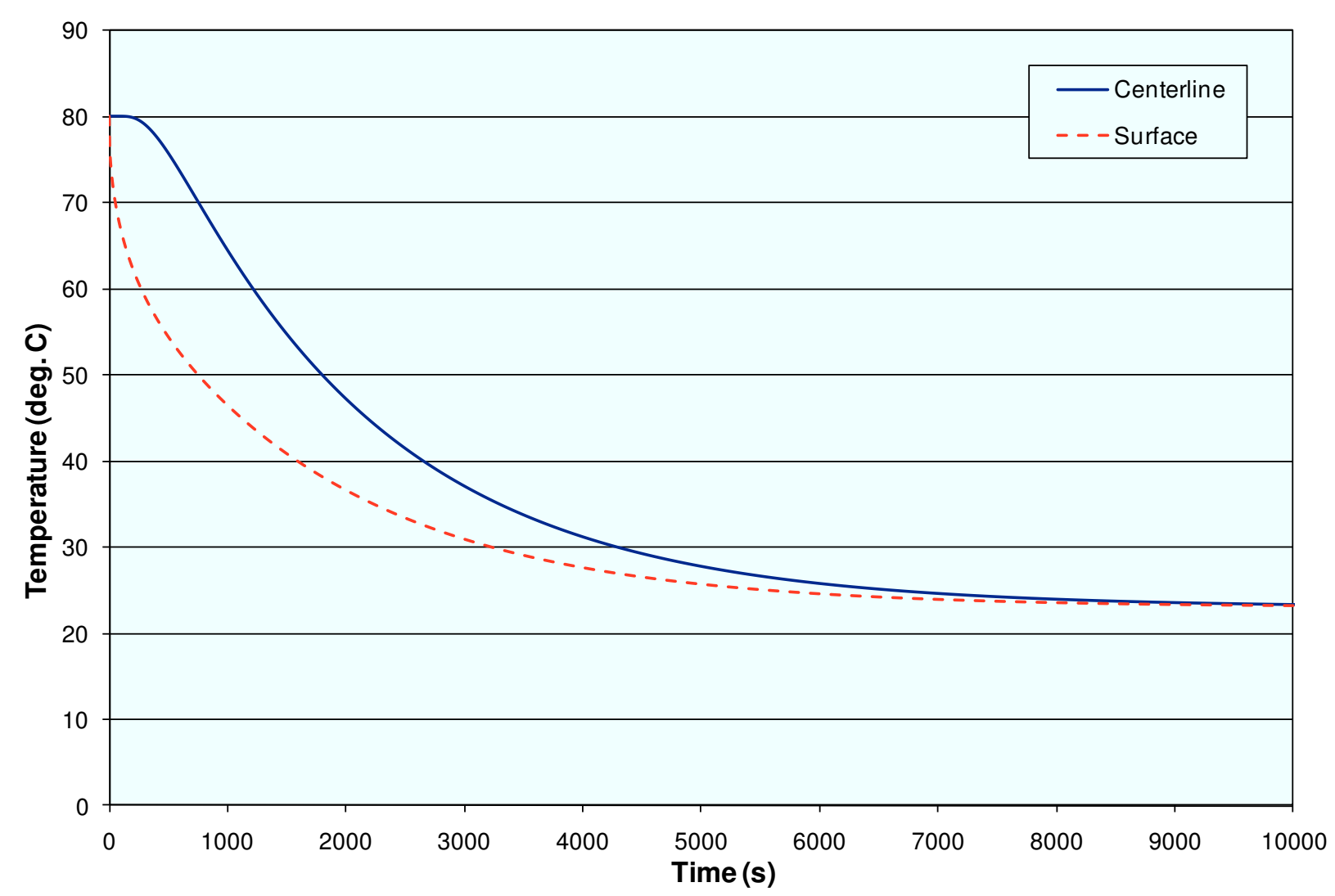

Figure 3: Temperature distribution of acrylic cylinder with time.

\section{Experiment}

This heat transfer study was revisited by the same set of students the following semester in their Systems and Measurement course. There students experimentally measured the cooling at the centerline and surface of a test cylinder. The primary goal of the laboratory was to determine an estimate of the heat transfer coefficient for the cooling cylinder under free convection cooling. This was to be done by fitting a trend line to collected cooling data, where the coefficients of the trend line are directly related to the desired coefficient. Accordingly, the assumption of lumped capacitance, which is used in estimating the heat transfer coefficient, is tested through a comparison of the surface and core temperature measurements. The exercise was also used to give the students an early-semester exposure to the many facets of experimental measurement.

At the start of the lab exercise, a team of students presented a review of the numerical study done the previous semester. Students were then instructed to assemble the hardware and software necessary to collect relevant temperature data. The experimental set up is shown in Figure 3. Using a Fluke Type-K thermocouple probe module (Fluke 80TK) with a Type K immersion probe (Fluke 80PK-22) in connection with a National Instruments CompactDAQ (NI cDAQ9172) containing the Analog In module (NI 9215), students were able to sample analog voltages proportional to the core temperature of the cylinder, which for the experiment is assumed to be 
the same as the surface temperature. The data was recorded using a Lenovo T61 laptop using National Instruments LabVIEW 8.6.

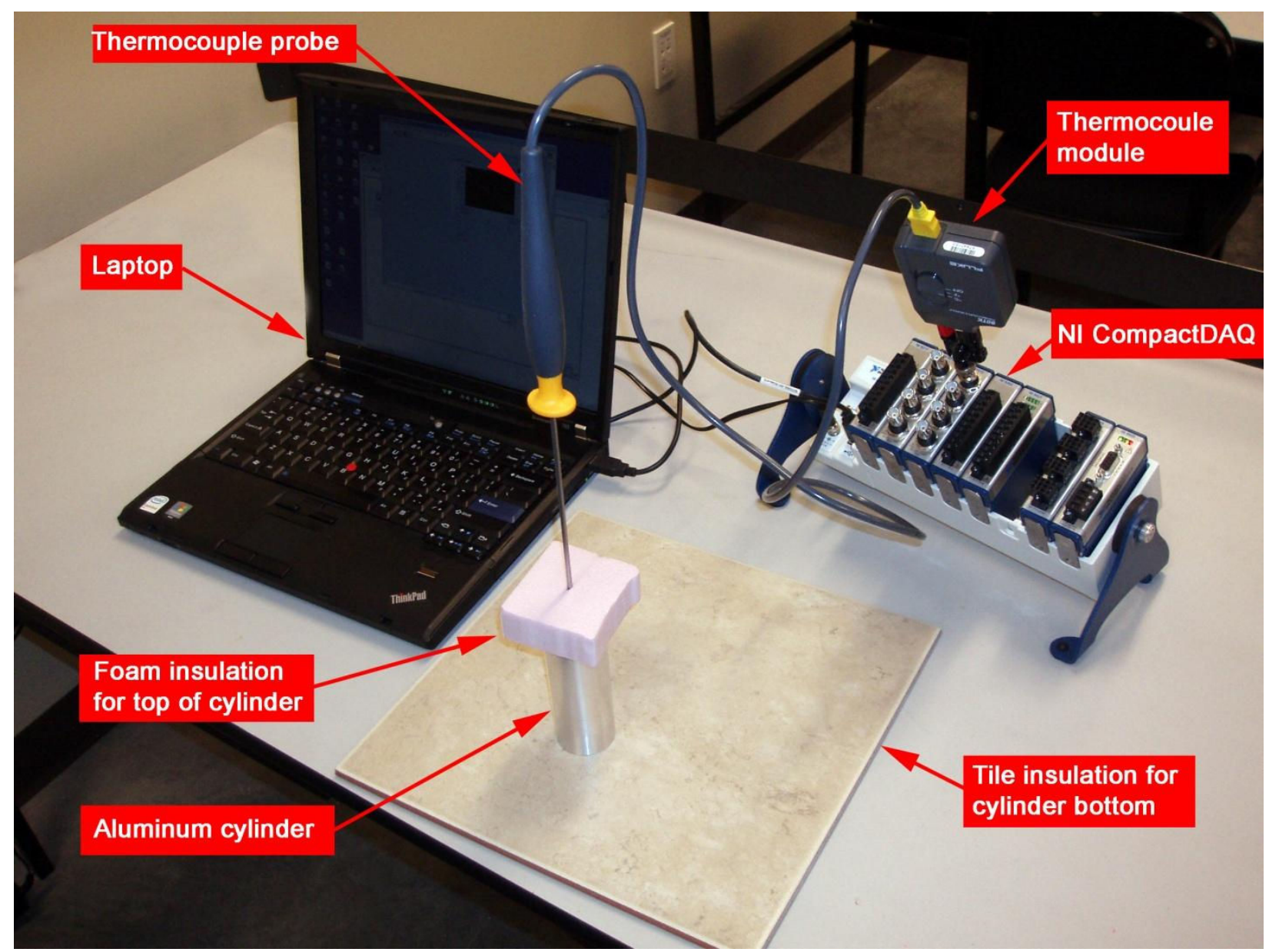

Figure 4: Photo of experimental set-up.

Prior to collecting data, students worked through a LabVIEW tutorial in which they were guided through the development of the data acquisition and conditioning of the measurements to be made. In the 2008 study, the separation of code development and data collection was not pronounced, and it was felt that the concepts would be more appreciable if they were done in stages. Students spent roughly three hours developing the code to be used and learning the fundamentals of LabVIEW. Then, in a subsequent meeting, the code was tuned and implemented to collect the temperature variations of the cooling cylinder.

An understanding of the static and dynamic characteristics of the sensors and the temperatures to which they would be exposed allowed students to make intelligent selections for input range and sample rate. Calibration information for the sensor was used to convert the input voltages to a temperature in degrees Celsius. Significant noise was in the analog signal and students were able to gain insight into the level of filtering and averaging that would allow them to collect

meaningful time response data. The LabVIEW program displayed the time histories on the Front Panel for real-time monitoring while saving the recorded data for post processing. 
Students then retrieved a small cylinder, either aluminum or acrylic, that had been heated to a temperature of $80^{\circ} \mathrm{C}$ in the oven provided (Cole Parmer StableTemp Gravity Convection Oven). Upon removing the cylinder from the oven, students placed one thermocouple in the tap drilled to the cylinder's center. An additional thermocouple was fixed with electrical tape to the surface of the cylinder midway along its length. With this, students recorded the temperatures as the cylinder cooled under ambient conditions.

In analyzing the results, the two cylinder types were found to behave differently. Data from the acrylic cylinder indicated a dramatic difference in the surface and core temperatures, thereby invalidating the lumped capacitance assumption. In the case of the aluminum cylinder it was seen that the core and surface temperatures were reasonably close, therefore the assumption was validated. An analysis of the data was done to determine the heat transfer coefficient for the aluminum cylinder. Assuming a constant temperature throughout the cylinder, as was confirmed in the theoretical analysis, the temperature of the cylinder can be related to the heat transfer coefficient with the following equation ${ }^{8}$.

$$
\frac{\mathrm{T}-\mathrm{T}_{\infty}}{\mathrm{T}_{\mathrm{i}}-\mathrm{T}_{\infty}}=\exp \left[-\left(\frac{\mathrm{t}}{\tau}\right)\right]
$$

Where $T$ is the temperature of the cylinder, $T_{\infty}$ is the air temperature, $T_{i}$ is the initial temperature, $\mathrm{t}$ is time, and $\tau$ is the time constant of the system, $\tau=\rho \mathrm{Vc} /\left(\mathrm{hA_{s }}\right)$. In the equation for the time constant, $\mathrm{h}$ is the heat transfer coefficient, $\mathrm{A}_{\mathrm{s}}$ is the surface area, $\rho$ is the density, $\mathrm{V}$ is the volume, and $\mathrm{c}$ is the specific heat of the cylinder. In this way, the heat transfer coefficient was related to the time constant of the experimental system. An exponential curve fit resulted in an estimate of the time constant $\tau$. With this estimation, the cylinder's known geometry, and tabulated values for the density and specific heat of aluminum, the heat transfer coefficient was calculated.

\section{Results and Discussion}

Upon completion of the experiment the students were given a survey to rate the effectiveness of the two part exercise. The questions and results are shown in Table 1 for both the 11-student 2008 study and for the enhanced 2009 study, which had 16 participants. For questions one through five students were asked to respond based on the following scale: 5 - strongly agree, 4 agree, 3 - no opinion, 2 - disagree, and 1 - strongly disagree. For questions six and seven, the scale was given with: 5 - full, 4 - high, 3 - medium, 2 - low, and 1 - none. 
Table 1: Student Survey and Response.

\begin{tabular}{|l|c|c|}
\hline \multicolumn{1}{|c|}{$\begin{array}{c}\text { Survey } \\
\text { Statement }\end{array}$} & $\begin{array}{c}\text { Mean } \\
\text { Response } \\
\text { 2008 Study }\end{array}$ & $\begin{array}{c}\text { Mean } \\
\text { Response } \\
\text { 2009 study }\end{array}$ \\
\hline $\begin{array}{l}\text { 1. The experiment helped to increase my understanding of } \\
\text { heat transfer. }\end{array}$ & 3.00 & 4.00 \\
\hline $\begin{array}{l}\text { 2. Similar experiments should be developed related to } \\
\text { other topics discussed in lecture courses. }\end{array}$ & 4.36 & 4.49 \\
\hline $\begin{array}{l}\text { 3. I clearly see the link between the experimental } \\
\text { measurements and the numerical simulation completed in } \\
\text { heat transfer }\end{array}$ & 4.09 & 4.00 \\
\hline $\begin{array}{l}\text { 4. The experiment gave me a better understanding of the } \\
\text { heat transfer coefficient and time constant. }\end{array}$ & 3.18 & 3.44 \\
\hline $\begin{array}{l}\text { 5. Conducting the experiment before conducting the } \\
\text { theoretical analysis would be more beneficial than the } \\
\text { current order of events. }\end{array}$ & 2.55 & 2.25 \\
\hline $\begin{array}{l}\text { 6. Level of understanding after completing the theoretical } \\
\text { analysis in heat transfer (ME336) }\end{array}$ & 4.27 & 3.88 \\
\hline $\begin{array}{l}\text { 7. Level of understanding after completing both the } \\
\text { theoretical analysis (ME336) and the experimental } \\
\text { analysis (ME491) }\end{array}$ & 4.36 & 4.36 \\
\hline
\end{tabular}

In looking at questions one and four, students had a marked increase in their appreciation of the experiment as it provided better understanding to the heat transfer phenomenon being studied. These are the most significant increases in evaluation scores, and they indicate that the modifications were effective.

Results for survey questions two, three, and five indicate that the students would value the development of similar cross curricular exercises wherein experiment is used to compliment theory and simulation. Question five specifically addresses the timing of the experiment and students prefer the experiment to be conducted after the theoretical analysis. An elective course in Systems and Measurement is ideal for this implementation, and with the students already familiar with LabVIEW basics, it could be a time- efficient application.

Students did indicate a drop in their level of understanding after completing just the theoretical analysis in Heat Transfer. It is suspected that this drop in score was necessitated by the noted gain in understanding associated with the experiment. Students did maintain their high level of understanding after completing both the theoretical analysis and the experimental analysis.

\section{Conclusion}

Based on the results of the survey, students found the modifications to the exercise beneficial to their learning. A student led review of the numerical study was complimented with a deliberate separation of code development and data collection. Additionally, the use of core and surface 
temperature readings and the inclusion of a new material type allowed students to examine model validation.

While the two part study was deemed a success, future modifications are under consideration. On the experimental side, more attention can be given to collecting accurate surface temperature measurements. This will likely result in the selection of a new sensor, and could lead to a more rigorous calibration of the measurement devices. This would be to the benefit of the students in Systems and Measurement.

Forced convection could also be implemented in both the simulation and experiment. It would provide an appreciation of another Heat Transfer phenomenon while giving students a window into the actuation side of LabVIEW. Furthermore, many of the calculations that are done in the post processing could be implemented in real-time on the front panel of the LabVIEW code. This, too, could be a useful learning experience for the students.

Related to survey, improvements can be made in the questions asked of the students. In particular, questions can be presented in a manner that allows for identification of the amount of improvement associated with each of the procedural modifications. Additionally, as the number of participating students grows, a more rigorous statistical analysis will be warranted.

\section{Bibliographic Information}

1. O'Halloran, S.P. and T.A. Doughty, "Integration of Numerical Analysis and Experimental Testing Involving Heat Transfer for a Small Heated Cylinder During Cooling," 2009 ASEE Annual Conference and Exposition, 2009, American Society of Engineering Education.

2. Besser, R.S., "Spreadsheet Solutions to Two-Dimensional Heat Transfer Problems," Chemical Engineering Education, Vol. 36, No. 2, 2002, pp. 160-165.

3 Churchill, S.W., "A New Approach to Teaching Turbulent Thermal Convection," Chemical Engineering Education, Vol. 36, No. 4, 2002, pp. 264-270.

4. Henda, R., "Computer Evaluation of Exchange Factors in Thermal Radiation," Chemical Engineering Education, Vol. 38, No. 2, 2004, pp. 126-131.

5. Goldstein, A.S., "A Computational Model for Teaching Free Convection," Chemical Engineering Education, Vol. 38, No. 4, 2004, pp. 272-278.

6. Feisel, L.D. and A.J. Rosa, "The Role of the Laboratory in Undergraduate Engineering Education", Journal of Engineering Education, Vol. 94, No. 1, 2005, pp. 121-130.

7. Clausen, E. and W. Penney, "Laboratory Demonstrations/Experiments in Free and Forced Convection Heat Transfer," 2006 ASEE Annual Conference and Exposition, 2006, American Society of Engineering Education.

8. Hunkeler, D. and J.E. Sharp, "Assigning Functional Groups: The Influence of Group Size, Academic Record, Practical Experience, and Learning Style,” Journal of Engineering Education, Vol. 86, No. 4, 1997, pp. 321332.

9. Incropera, F.P., D.P. DeWitt, T.L. Bergman, and A.S. Lavine, "Introduction to Heat Transfer, $5^{\text {th }}$ Edition," John Wiley \& Suns, 2007. 
10. Hoffman, J.D., "Numerical Methods for Engineers and Scientists, $2^{\text {nd }}$ Edition" Taylor and Francis, Inc., 2001.

Dै
$\stackrel{0}{0}$
$\mathbb{D}$
$\vec{N}$
$\stackrel{N}{\omega}$
$\vec{N}$ 